\title{
Complimentary Effects of Curcumin for Enhancing Efficacy of Acetylsalicylic Acid against Prostate Cancer
}

\author{
Tapas Kumar Mohapatra', Debasish Mohapatra², Bharat Bhusan Subudhi1,* \\ ${ }^{1}$ Drug Development and Analysis Laboratory, School of Pharmaceutical Sciences, Siksha 'O' Anusandhan (Deemed to be University), \\ Bhubaneswar, Odisha, INDIA. \\ ${ }^{2}$ Tumor Microenvironment and Animal Models Laboratory, Department of Translational Research, Institute of Life Sciences, \\ Bhubaneswar, Odisha, INDIA.
}

\begin{abstract}
Background: Prostate cancer is the $6^{\text {th }}$ leading cause of cancer death worldwide. Androgen Deprivation Therapy (ADT) in prostate cancer enhances the risk of Rheumatoid Arthritis (RA). Acetylsalicylic Acid (ASA) can be potentially repurposed against prostate cancer and arthritis. However, its efficacy is low and use is associated with nephrotoxicity as well as gastrotoxicity. Curcumin with reported ability to potentiate anti-inflammatory effects and reduce oxidative stress, can be used as a complementary therapy to enhance efficacy of ASA against prostate cancer and arthritis. This can also minimise ASA induced nephrotoxicity and gastrotoxicity. Aim and Objectives: To evaluate the ability of curcumin to enhance efficacy of ASA against prostate cancer, arthritis while minimising its adverse effects. Methods: In-vitro anticancer activity was assessed in DU-145 (Androgen-independent) and LNCaP (Androgen-dependent) cells. Effect against arthritis was evaluated in complete Freund's adjuvant (CFA) induced arthritis model in rats. Biochemical factors, radiology and histopathology were examined. Protection against kidney dysfunction and ulceration was determined. Results: Curcumin on co-administration with ASA (ASA + Cur) $(25 \mu \mathrm{M}+25 \mu \mathrm{M})$ showed higher efficacy against DU-145 and LNCaP cell model. This co-use showed significant $(p<0.001)$ inhibition of arthritis index (AI). The erythrocyte sedimentation rate (ESR) and rheumatoid factor (RF) were significantly $(p<0.001)$ decreased from their elevated level. It also reduced tumor necrosis factor $\alpha$ (TNF- $\alpha$ ), interleukin $1 \beta$ (IL-1 $\beta$ ) and interleukin 6 (IL-6) at the molecular level. While it showed moderate gastro-protection, there was no adverse effect on kidney functions. Conclusion: Curcumin seems to enhance the effect of ASA against androgen dependent as well as androgen independent prostate cancer while reducing arthritis. Simultaneously, it reduces ASA induced gastrotoxicity and prevents nephrotoxicity.
\end{abstract}

Key words: Acetylsalicylic acid, Androgen deprivation, Prostate cancer, Arthritis index, Gastric ulcer.

\section{INTRODUCTION}

Drug repurposing is an important alternative to new drug discovery for developing new therapeutic strategies. ${ }^{1}$ Optimization of pharmacokinetic or pharmacodynamic through use of complementary drugs/herbs is an interesting option to maximize the therapeutic benefits. ${ }^{2}$ ASA has successfully been repurposed against different conditions including inflammation and cardiovascular disorder. It has also been shown to be effective against many form of cancer in-vitro. ${ }^{3-5}$ While its ability to inhibit cyclooxygenase (COX) explains most of its therapeutic benefits, its COX-independent anticancer effects are primarily mediated by inhibition of nuclear factor kappa-light-chain-enhancer of activated B cells (NF-kB). ${ }^{6}$ Considering its low potency $\left(\mathrm{IC}_{50} \geq 50 \mu \mathrm{M}\right)$ against NF-kB,
Submission Date: 17-08-2019; Revision Date: 26-09-2019; Accepted Date: 10-10-2019

DOI: 10.5530/ijper.53.4s.163 Correspondence: Dr. Bharat Bhusan Subudhi, Drug Development and Analysis Laboratory, School of Pharmaceutical Sciences, Siksha 'O' Anusandhan (Deemed to be University), Bhubaneswar-751029, Odisha, INDIA. Phone: +91-9853945363 E-mail: Bharatbhusans@ gmail.com

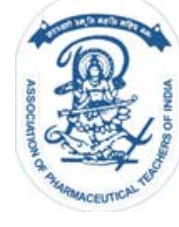

www.ijper.org 
a higher dose is desirable for translation of its in-vitro potential to in-vivo efficacy. ${ }^{7}$ Since at higher dose it is associated with gastrotoxicity, hepatotoxicity and nephrotoxicity, the therapeutic benefits are limited. ${ }^{8-10}$

Prostate cancer is the $6^{\text {th }}$ leading cause of cancer death worldwide as 1.3 million men are diagnosed with prostate cancer annually. ${ }^{11}$ In the initial stages, its growth is androgen-dependent. Accordingly, ADT is adopted to manage prostate cancer during early stage. ${ }^{12}$ Since suppression of androgen hormones leads to $\mathrm{RA}$, patients undergoing ADT are prone to the risk of arthritis. ${ }^{13}$ ASA with its anti-inflammatory and anticancer potential can be expected to show effects against prostate cancer and arthritis. However, the in-vitro effects against prostate cancer have not been very promising. This is because at relatively higher doses $(2-5 \mathrm{mM})$ only $10-40 \%$ reduction in cell viability has been demonstrated. ${ }^{14-16}$ Further, the human dose of ASA is reported to be relatively high against inflammation $(1 \mathrm{gm} /$ day $)$ and arthritis $(3.6 \mathrm{gm} /$ day $) .^{17,18}$ At these doses, ASA is associated with gastrotoxicity, hepatotoxicity and nephrotoxicity. Thus it is necessary to adopt alternative startegy to enhance the efficacy of ASA against prostate cancer and arthritis.

Earlier, curcumin has been shown to inhibit prostate cancer and reduce arthritis. ${ }^{19,20}$ It has also been shown to reduce gastrotoxicity and hepatotoxicity. ${ }^{21,22}$ The additive anti-inflammatory effects of curcumin with ASA were recently shown by us. ${ }^{22}$ Considering these, curcumin can be expected to complement the efficacy of ASA against prostate cancer and arthritis. It may also protect against ASA induced gastrotoxicity and nephrotoxicity owing to its ability to reduce oxidative stress.

With the above consideration, this study was undertaken to assess the complementary benefits of ASA+Cur. The effect against prostate cancer was studied in ADT dependent and ADT independent prostate cancer in-vitro models. Efficacy was also studied against arthritis. Effects on kidney function, cytokine level and gastric mucosa were studied to justify their potential therapeutic application. This aims to demonstrate the complementary benefits of curcumin when co-administered with ASA and may encourage the repositioning of ASA against prostate cancer and arthritis.

\section{MATERIALS AND METHODS}

\section{Drugs and chemicals}

ASA and curcumin ( $\geq 90 \%$ purity) were procured from Hi-media laboratories (Nasik, India). The CFA was supplied by Sigma Chemicals Company, St. Louis, USA. Pure diclofenac and ranitidine were gifted by
Odisha Drugs and Chemical Ltd, Bhubaneswar, India. For the experimental study all reagents and chemicals were of analytical grade obtained from local firms (India).

\section{Cancer cell lines}

The experiments were performed using the DU-145 (ADT-independent) and LNCaP (ADT-dependent) human prostate cancer cell line obtained from American Type Culture Collection (ATCC, Rockville, MD). Both cells were cultured in Dulbecco's Modified Eagle Media (DMEM Invitrogen, Carlsbad, CA) added to heat-inactivated fetal bovine serum $(7 \%)$, glutamine $(2 \mathrm{mmol} / \mathrm{L})$, non-essential amino acids $(0.1 \mathrm{mmol} / \mathrm{L})$, HEPES buffer $(10 \mathrm{mmol} / \mathrm{L})$ and streptomycin $(100 \mathrm{U} / \mathrm{mL})$. The cultures were incubated at $37^{\circ} \mathrm{C}$ in $5 \% \mathrm{CO}_{2}$ incubator.

\section{Animal used}

Wistar rats (180-200 g) are used in the present studies were procured from animal house facility School of pharmaceutical sciences (SPS), Siksha 'O' Anusandhan (Deemed to be university), India, bearing Reg. no. 1171/PO/Re/S/08/ CPCSEA. Animals were housed in polypropylene cages. The animals were acclimatized to the laboratory condition for 1 week before starting the experiment. The animals were fasted for at least 12 $h$ before the onset of each activity. The animals received the drug treatments by oral gavage tube. All experiments were performed with due approval of Institutional animal ethics committee (IAEC), as per approval no. (IAEC/SPS/SOA/13/2019). The albino rats were maintained under standard environmental conditions $(60$ $\pm 5 \%$ relative humidity, $25 \pm 2^{\circ} \mathrm{C}$ temperature and $12 \mathrm{~h}$ light/dark cycle). The animals were feed with standard laboratory pellet diet and water ad-libitum. Both gender of rats were used for the study.

\section{In-vitro anti-cancer activity MTT assay}

DU-145 and LNCaP cells were seeded ( $5 \times 10^{3} /$ well) in $200 \mu \mathrm{L}$ of DMEM medium into 96-well plates and incubated for $24 \mathrm{~h}$ at $37^{\circ} \mathrm{C}$ in $5 \% \mathrm{CO}_{2}$. Further, cells were exposed to cisplatin $(25 \mu \mathrm{M})$ (standard), ASA $(25 \mu \mathrm{M})$, curcumin $(25 \mu \mathrm{M})$, ASA+Cur $(25 \mu \mathrm{M}+25$ $\mu \mathrm{M})$ and vehicle control in dimethyl sulfoxide (DMSO) $(0.1 \%)$, then again incubated for $48 \mathrm{~h}$. Further, cells were incubated for additional $4 \mathrm{~h}$ with MTT (2.41 $\mathrm{mmol} / \mathrm{L}$ ) (Sigma Chemicals Company, St. Louis, USA). The formazan crystal formed by living cells were dissolved in DMSO $(100 \mu \mathrm{L})$ after removing supernatant and plates were shaken gently at room temperature for $1 \mathrm{~h}$. At $550 \mathrm{~nm}$ (Ranin microtiter plate reader) plate 
reading were taken and absorbance values were obtained. All experiments were analyzed in triplicate. The reading reflected the number of viable cells. The effect of drugs on cell viability (CV) (\%) was calculated. ${ }^{23}$

$$
\mathrm{CV}(\%)=\{(\mathrm{Ac}-\mathrm{At}) / \mathrm{Ac}\} 100
$$

Where, Ac and At are the absorbance of control and treated cells, respectively.

From, percentage of $\mathrm{CV}$, growth inhibition was calculated; where vehicle treated cells were considered as $100 \%$ viable.

Further, it was confirmed by crystal violet assay and analysed using light microscopy (Microscope- Magnus, New Delhi, India, Photographic camera- Olympus Imaging Corporation, New Delhi, India).

\section{Morphological observation}

Morphological changes in DU-145 and LNCaP cells were observed after $(72 \mathrm{~h})$ treatment using light microscopy (Bright field image).

\section{Colony formation assay}

Colony formation assay tests each cell for its ability to undergo unlimited division in the population. However, cell reproductive death determined by clonogenic assay. Both prostate cancer cells (DU-145 and LNCaP) were seeded in culture plates (500 cells per well), incubated for $24 \mathrm{~h}$ at $37^{\circ} \mathrm{C}$ with $5 \% \mathrm{CO}_{2}$ and treated with cisplatin, ASA, curcumin and ASA+Cur. DMSO was added to both the cells media and incubated at $37^{\circ} \mathrm{C}$ in $5 \% \mathrm{CO}_{2}$. After 7 days, colonies were washed in phosphate buffer saline (PBS) and stained with crystal violet $(0.5 \% \mathrm{w} / \mathrm{v})$. Further, colonies were washed, dried in air and evaluated using light microscopy. ${ }^{24}$ Colony count was quantified by image J software and survival fraction (SF) was determined. All experiments were analyzed in triplicate.

$\mathrm{SF}=$ treatment colony numbers/control colony numbers

\section{In-vivo anti-arthritic activity}

\section{Induction of Arthritis}

CFA was injected $(0.1 \mathrm{~mL})$ in the left metatarsal footpad of rat's hind paw to induce arthritis. ${ }^{25}$ All drugs were dissolved with $3 \mathrm{~mL}$ of $1 \%$ carboxy methyl cellulose (CMC) in distill water to prepare a crude suspension and was administered immediately by p.o. (per oral) route. All drugs and treatment was started 30 min before CFA injection ( 0 day) and continued upto $28^{\text {th }}$ days. ${ }^{26}$ For the evaluation of anti-arthritic activity the Wistar rats divided into six groups $(n=6)$ for 28 days treatment:

Group 1: Normal Control- Administered water ad-libitum Group 2: Arthritic control- Treated with CFA (0.1 mL)
Group 3: Standard- Arthritic animal + Treated with diclofenac (10 mg/kg, p.o.)

Group 4: Arthritic animal + Treated with ASA (100 mg/kg, p.o.) by using a human-rat conversion factor Group 5: Arthritic animal + Treated with curcumin (200 $\mathrm{mg} / \mathrm{kg}$, p.o.) by using a human-rat conversion factor

Group 6: Arthritic animal + Treated with ASA+Cur (100 mg/kg $+200 \mathrm{mg} / \mathrm{kg}$, p.o.)

The paw thickness was quantified by Vernier calliper (Mitutoyo, Japan) on 0, 7, 14, 21 and 28 days respectively after CFA injection. On the $29^{\text {th }}$ day animals were sacrificed by cervical decapitation, fixed hind legs and kidney were removed preserved in formalin $(10 \%)$ for further study. Blood was drawn by cardiac puncture and kept in both ethylenediaminetetraacetic acid (EDTA) as well as plain tubes. Then samples were centrifuged (REMI Cooling centrifuge, C-24BL, Mumbai, India) at $89.44 \times \mathrm{g}$ for $10 \mathrm{~min}$ and the supernatant (serum) was stored at $-80^{\circ} \mathrm{C}$ (REMI Ultra low freezer, UDF-85, Mumbai, India) for analysis.

\section{Al and Inhibition of paw-thickness}

From paw thickness value AI (\%) and inhibition of paw thickness $(\%)$ was calculated. ${ }^{26,27}$ The formula is as follows:

AI $(\%)=($ Hind paw thickness on day $\mathrm{x}-$ Hind paw thickness on day 0$) \times 100 /$ Hind paw thickness on day 0 Inhibition of paw-thickness $(\%)=(\mathrm{Mc}-\mathrm{Mt}) \times 100 / \mathrm{Mc}$ Where, Mc is the measure of rat paw edema in the CFA treated animal group and $\mathrm{Mt}$ is the measure of rat paw edema of the drug treated animal group.

\section{Assessment of arthritis through histological and radiological analysis of hind paw}

The fixed hind legs joints were excised, removed, cleaned in saline and preserved in formalin (10\%). For decalcification the proximal ankle joint was subjected $5 \%$ nitric acids for 7 days. Following paraffin embedding, these are stained with Hematoxylin-eosin $(\mathrm{H}$ and E) and studied using light microscopy. Inflammation degree was assessed as per standard method. ${ }^{28}$ For radiological analysis (Dental X-ray, Mediray Healthcare Pvt. Ltd. New Delhi, India) the arthritis induced hind legs of rats were taken and analyzed for narrowing of the joints space, bony erosions and soft tissue swelling. ${ }^{29}$

\section{Assessment of haematological and biochemical parameter}

Haematological and biochemical examination of blood and serum samples were done by employing standard procedures and tests. ${ }^{30,31}$ For assessment of hematological 
and biochemical study, parameters including ESR, RF, urea and creatinine were evaluated.

\section{Assessment of Kidney through histological analysis}

Tissue sections of kidney were dehydrated, embedded in paraffin, stained with $\mathrm{H} \& \mathrm{E}$ and examined with the help of light microscopy.

\section{Assessment of Cytokines production}

The levels of serum cytokines were determined by ELISA (Assay kits-Sigma Chemicals Company, USA), employing standard procedures. Serum samples $(100 \mu \mathrm{L})$ of the respective groups were added to each well and incubated for $2.5 \mathrm{~h}$ followed by prepared biotin antibodies (TNF- $\alpha$, IL-1 $\beta$ and IL-6) $(100 \mu \mathrm{L})$ was added to each well and incubated for $1 \mathrm{~h}$. Further, prepared Streptavidin solution $(100 \mu \mathrm{L})$ was added and incubated for $45 \mathrm{~min}$ at room temperature. Then, to each well tetramethylbenzidine (TMB) $(100 \mu \mathrm{L})$ was added and blue colour was developed in respect to the amount of antibody bound which was further incubated for 30 min. Lastly, to each well stock solution $(50 \mu \mathrm{L})$ was added, the colour changed from blue to yellow and reading was noted at $450 \mathrm{~nm}$. After each step washed with buffer solution for four times. The TNF- $\alpha$, IL-1 $\beta$ and IL- 6 protein were quantified by comparing the sample to the standard curve generated. The results were expressed as $\mathrm{pg} / \mathrm{mL}$ protein. ${ }^{32}$

\section{Assessment of gastro-protective activity Induction of Ulcer}

For assessment of gastro-protective activity ASA induced gastric ulceration model was employed in rats. A similar trend in drugs preparation was maintained as mentioned above. All drugs and treatment was given for 28 days. For gastroprotective activity, the animals were divided into four groups $(n=6)$.

Group 1: Normal Control- Administered water ad-libitum Group 2: Gastric ulcer control- ASA (100 mg/kg, p.o.)

Group 3: Standard- ASA+ ranitidine $(100 \mathrm{mg} / \mathrm{kg}+25$ $\mathrm{mg} / \mathrm{kg}$, p.o.)

Group 4: ASA+Cur (100 mg/kg + $200 \mathrm{mg} / \mathrm{kg}$, p.o.)

On the $29^{\text {th }}$ day animals were sacrificed by cervical decapitation, stomach were removed, opened along the greater curvature and rinsed with $5.0 \mathrm{~mL}$ of $0.9 \% \mathrm{NaCl}$ to remove gastric content and blood clots and then ulcer were quantified using light microscopy. Ulcerated tissue was stored in 10\% formalin for further analysis. The Ulcer index (UI) and Protective index (PI) was evaluated. . $3-34^{-34}$

\section{UI and PI}

$$
\mathrm{UI}=\text { Area of ulcers } \times 100 / \text { Total stomach area }
$$

(Ulcer index control -

PI or Inhibition of ulceration $(\%)=\frac{\text { Ulcer index test })}{\text { Ulcer index Control }} \times 100$

\section{Assessment of stomach through histological analysis}

Tissue section of stomach were dehydrated, embedded in paraffin, stained with $H \& E$ and examined with the help of light microscopy. ${ }^{34}$

\section{Statistical analysis}

All the data were represented as mean \pm Standard Deviation (SD). For statistical analysis One-way analysis of variance (ANOVA) followed by Bonferroni multiple comparison test was applied using XLSTAT software student's version. $(p<0.001)$ considered as statistically significant. All treatment groups were compared with disease control group (Cancer associated control, Arthritic control/only CFA treated group and ulcerated control).

\section{RESULTS}

\section{In-vitro Anti-cancer activity}

MTT assay result showed that ASA+Cur exhibited a very strong anticancer effect compared to ASA and curcumin individually. It approximately killed 66\% cells of DU-145 and 58\% cells of LNCaP. Whereas, cisplatin approximately killed 55\% cells of DU-145 and LNCaP (Figure 1A and B). As shown in (Figure S1) crystal violet assay also showed the same.

The morphology of DU-145 and LNCaP cells are star-shaped (typical morphology of DU-145 and LNCaP cells). The light microscopy revealed that on treatment both cells are shrunk, spacing between cells and deposition of particle of cytoplasm were observed in cisplatin and ASA treated groups but these feature were found less in curcumin treated groups. In ASA+Cur treated groups, this effect was stronger than individual treated group where larger spacing between cells, more deposition of particle of cytoplasm and alteration of cellular structure were seen which indicate early apoptosis (Figure 1C). Overall, after treatment cell lost their typical morphology.

Reductions in colony formation are visible following treatment with ASA and curcumin. This was more pronounced following treatment with ASA+Cur (Figure 1D). Quantitatively, in respect to cisplatin SF $(0.7 \%), \mathrm{ASA}+$ Cur showed less SF (approximately $0.5 \%$ ) in DU-145and LNCaP cells (Figure 1E and F). 
(A)

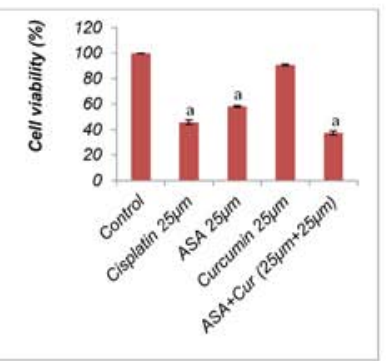

(B)

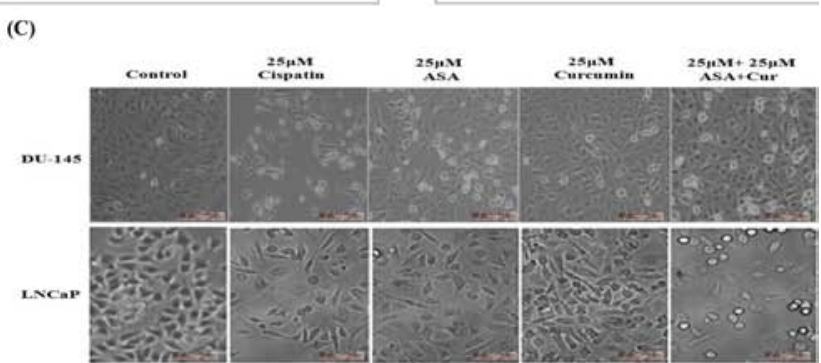

(D)

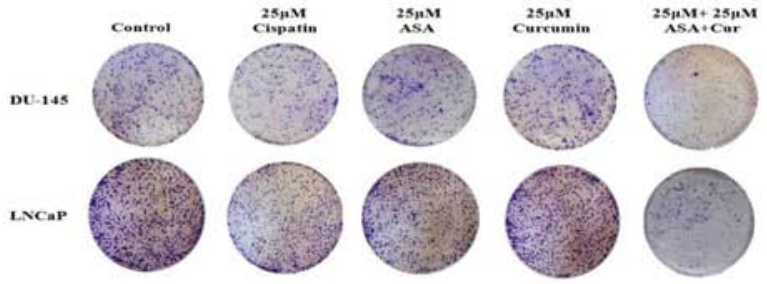

(E)

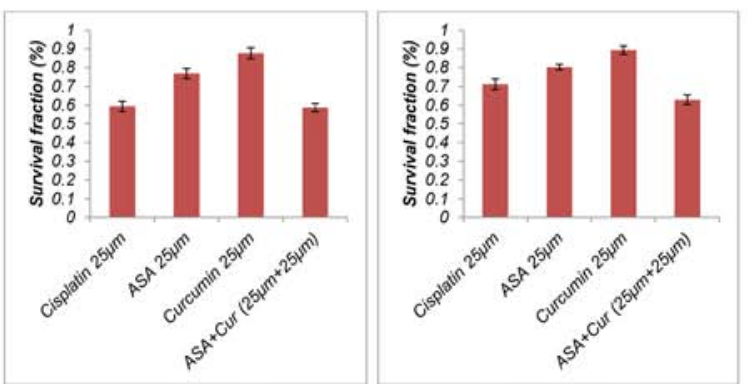

Figure 1: Effect of ASA+cur on the viability of DU-145 and LNCaP cancer cells (A) Cell viability by MTT assay of DU-145 cells (B) Cell viability by MTT assay of LNCaP cells (C) The Morphological Changes of DU145 and LNCaP cells after 72 $h$ of treatment (D) The colony forming assay using DU-145 and LNCaP cancer cells. Quantification of colony formation as indicated by the survival fraction in DU-145 (E) and LNCaP cell (F). The data are expressed as mean \pm standard deviation $(n=3) .{ }^{a} p<0.001$ vs control group. All the statistical analysis was done by one-way ANOVA followed by Bonferroni test.

\section{In-vivo anti-arthritic activity}

\section{Al and Inhibition of paw edema}

Following administration of CFA in hind paw, the paw thickness increased upto 7 days which indicated induction of arthritic conditions in rats. Animals treated with ASA + Cur showed a significant $(p<0.001)$ decrease in

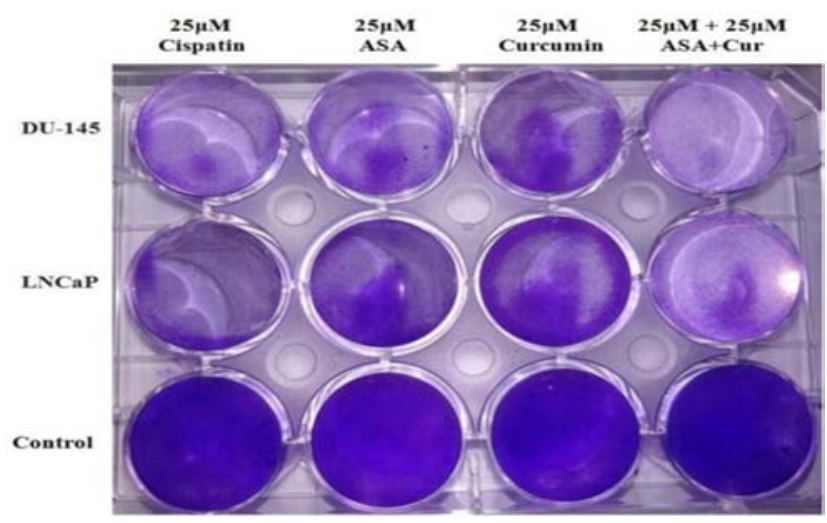

Figure S1: Representative photograph on Effect of ASA+cur on the viability of DU-145 and LNCaP cancer cells (crystal violet assay) $(n=3)$.

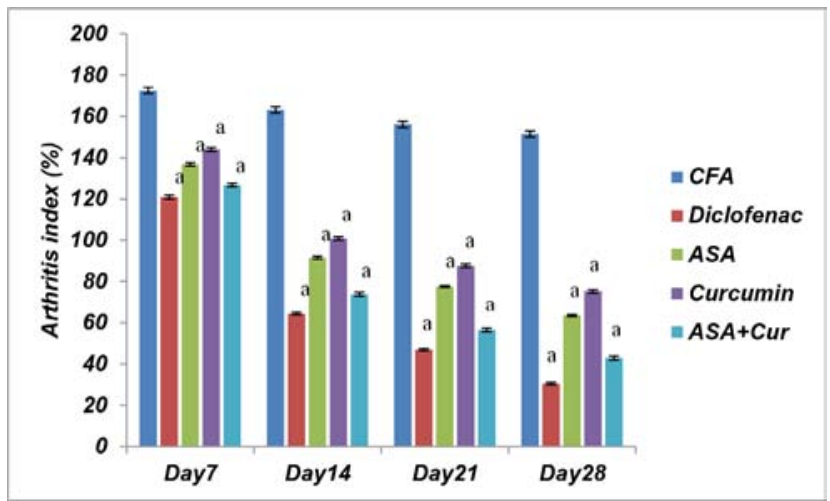

Figure 2: Effect of ASA+Cur on change in the arthritic index. The arthritic index calculated based on paw thickness value of rats treated with CFA. The data are expressed as mean \pm standard deviation $(n=6)$. ${ }^{a} p<0.001$ with respect to CFA treated group. All the statistical analysis was done by one-way ANOVA followed by Bonferroni test.

the severity of arthritis as shown by the reduction of AI throughout the experiment (Figure 2). The percentage of decrease in paw thickness of rats treated with ASA, curcumin and ASA+Cur in comparison to CFA-treated arthritic rats were $58.31 \%, 50.41 \%$ and $71.91 \%$ respectively (Figure S2). Diclofenac treatment produced high reduction in paw thickness as compared to arthritic control (Figure S2).

\section{Histological and radiographic analysis of hind paw}

Transverse section of hind legs of control rats showed normal bony architecture (Figure 3A). Following administration of CFA in the hind paw of animals, induction of arthritis was evident from prominent abnormalities. The synovial hyperplasia, huge infiltration of inflammatory exudates with bone and cartilage erosion were observed (Figure 3D). However, animals treated with diclofenac showed normal bone marrow, 


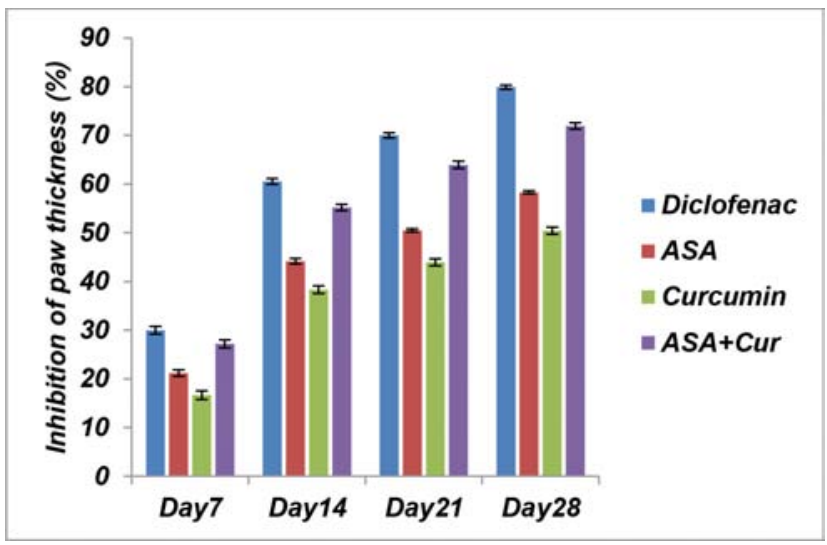

Figure S2: Effect on inhibition of paw thickness (\%) in arthritic rats. The data are expressed as mean $\pm \operatorname{SD}(n=6)$. All the statistical analysis was done by one-way ANOVA followed by Bonferroni test.

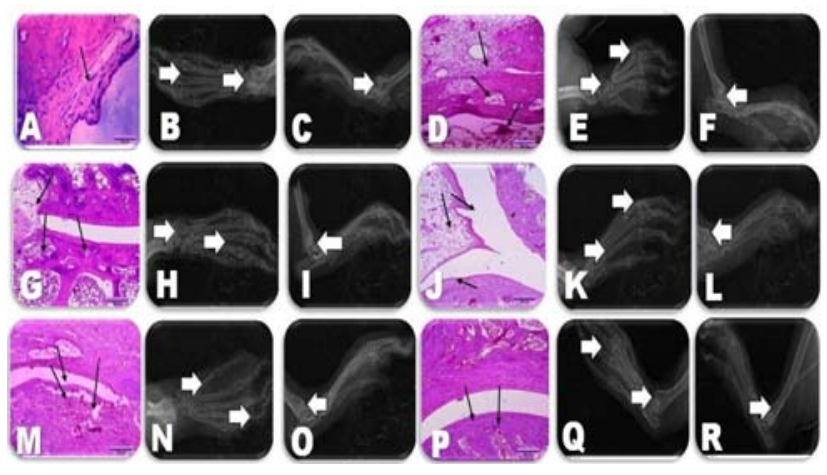

Figure 3: Representative photomicrographs of histopathological and radiographic changes of affected joints in arthritic rats. Control rats (A, B and C), CFA $(0.1 \mathrm{~mL})$ treated rats $(D, E$ and $F)$, Diclofenac (10 mg/kg) treated rats (G, $\mathrm{H}$ and $\mathrm{I})$, ASA (100 mg/kg) treated rats (J, K and L), Curcumin (200mg/kg) treated rats $(\mathrm{M}, \mathrm{N}$ and $\mathrm{O})$ and $\mathrm{ASA}+\mathrm{Cur}(100 \mathrm{mg} / \mathrm{kg}+200 \mathrm{mg} / \mathrm{kg})$ treated rats $(P, Q$ and $R)(n=6)$. The arrowheads indicate synovial hyperplasia, infiltration of inflammatory exudates, bone as well as cartilage erosion, soft tissue swelling and joint space narrowing in the hind paw and joints.

less cellular infiltrates but not able to maintain synovial hyperplasia (Figure 3G). The animals treated with ASA and curcumin alone were also able to reduce synovial hyperplasia. However, inflammatory signs and bony erosion was observed in the joints (Figure $3 \mathrm{~J}$ and $\mathrm{M}$ ). Whereas, ASA+Cur treatment showed powerful reduction of synovial hyperplasia. The inflammatory exudates and bone erosion were also found to be reduced similar to diclofenac (Figure 3P).

Radiology of hind leg of control rats showed absence of soft tissue swelling and bony destruction (Figure $3 \mathrm{~B}$ and $\mathrm{C})$. CFA injected animals developed joint space narrowing of the inter-tersal joints. The soft tissue swelling and extensive erosion suggests significant bone destruction and arthritic condition (Figure 3E and F). Treatment with the diclofenac prevented the bone destruction and swelling of the joint (Figure 3H and I). Unlike this, ASA treatment failed to prevent swelling of soft tissue and joint space narrowing signifying the existence of arthritic condition (Figure 3K and L). Similar observation was also made for curcumin treated groups (Figure 3N and O). Nonetheless, treatment with ASA+Cur reduced soft tissue swelling, bone destruction and joint space narrowing (Figure 3Q and $\mathrm{R})$.

\section{Haematological and biochemical parameter}

The comparison of the alteration in haematological and biochemical parameters in CFA induced arthritic rats to normal rats are shown in Table 1 . The challenge with CFA showed significant $(\phi<0.001)$ elevation in ESR count and RF. Individual treatment with ASA and curcumin significantly lowered both ESR count and RF. Treatment with the ASA+Cur further lowered these parameters. The effects on the reduction of ESR count and RF were comparable to that of the diclofenac (Table 1).

\section{Serum urea and creatinine}

The levels of urea and creatinine were found to be higher in CFA induced arthritic rats compared to control animals (Table 2). Treatment with curcumin alone or ASA +Cur significantly $(p<0.001)$ reduced urea and creatinine level. Whereas, diclofenac and ASA treatment failed to prevent these alterations.

\section{Histological analysis of kidney}

Transverse section of kidney of control group animals did not reveal any appreciable histopathological alterations (Figure 4A). CFA treated animals showed loss of renal tubular structure where the renal tubules showed cellular swelling and protein casts accumulation in the tubular lumen. Also focal areas of necrosis were present (Figure 4B). Diclofenac treated rats showed congestion, vacuolation of cell lining and glomerular contraction (Figure 4C). ASA treated rat showed damage lumen cells and marked tubular atrophy with interstitial fibrosis (Figure 4D). Unlike the above, rats treated with curcumin did not reveal any appreciable histopathological alterations (Figure 4E). ASA+Cur treated rats showed normal interstitial connective tissue and prominent spherical nuclei (Figure 4F).

\section{Serum cytokine production}

In this study the serum TNF- $\alpha$ level of normal control group was found to be up regulated in serum of CFA induced arthritic rats and found to be $1.66 \pm 0.015 \mathrm{pg} /$ $\mathrm{mL}$. Treatment with diclofenac, ASA and ASA+Cur 


\begin{tabular}{|c|c|c|c|}
\hline $\begin{array}{l}\text { SL. } \\
\text { No }\end{array}$ & Group & $\operatorname{ESR}(\mathrm{mm} / \mathrm{h})$ & $\mathrm{RF}(\mathrm{IU} / \mathrm{mL})$ \\
\hline 1 & Control & $3.75 \pm 0.004$ & $9.16 \pm 0.105$ \\
\hline 2 & CFA $(0.1 \mathrm{~mL})$ & $10.36 \pm 0.005$ & $18.75 \pm 0.403$ \\
\hline 3 & Diclofenac $(10 \mathrm{mg} / \mathrm{kg})$ & $5.18 \pm 0.007^{a}$ & $11.00 \pm 0.000^{\mathrm{a}}$ \\
\hline 4 & ASA (100 mg/kg) & $8.17 \pm 0.011^{\mathrm{a}}$ & $14.33 \pm 0.105^{\mathrm{a}}$ \\
\hline 5 & Curcumin $(200 \mathrm{mg} / \mathrm{kg})$ & $9.96 \pm 0.004^{a}$ & $16.08 \pm 0.083^{a}$ \\
\hline 6 & $\begin{array}{c}\text { ASA+Cur (100mg/ } \\
\mathrm{kg}+200 \mathrm{mg} / \mathrm{kg})\end{array}$ & $7.54 \pm 0.027^{\mathrm{a}}$ & $12.60 \pm 0.063^{a}$ \\
\hline
\end{tabular}

$\mathrm{a}=$ Significant difference $(p<0.001)$ with respect to CFA treated group.

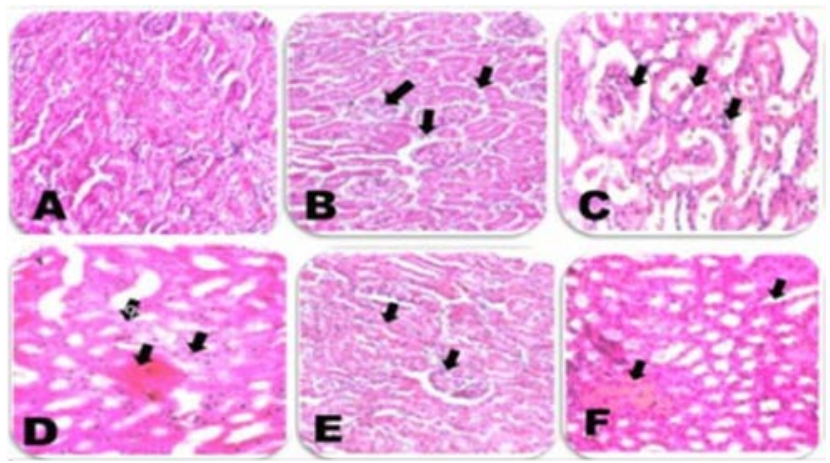

Figure 4: Representative photomicrographs of histopathological changes of kidney in arthritic rats. (A) Control rat, (B) CFA $(0.1 \mathrm{~mL})$ treated rats, $(C)$ Diclofenac $(10 \mathrm{mg} / \mathrm{kg})$ treated rats, (D) ASA (100 mg/kg) treated rats, (E) Curcumin $(200 \mathrm{mg} / \mathrm{kg}$ ) treated rats, (F) (ASA+Cur) $(100 \mathrm{mg} / \mathbf{k g}+200 \mathrm{mg} / \mathrm{kg})$ treated rats $(n=6)$. The arrowheads indicate alterations like swelling and necrosis.

for 28 days caused significantly $(p<0.001)$ less production of serum TNF- $\alpha$ in animals (Table 3). The serum IL-1 $\beta$ level of the CFA treated group $(4.16 \pm 0.011 \mathrm{pg} /$ $\mathrm{mL}$ ) was also found to be significantly $(p<0.001)$ higher than that of the normal control group. Following 28 days of treatment with diclofenac, ASA, curcumin and ASA + Cur the serum IL- $1 \beta$ level of animals were observed to be significantly $(\phi<0.001)$ lower than the toxic control (CFA treated groups). The inhibition was more pronounced in animals treated with diclofenac (Table 3). The serum IL-6 level of the control group was also significantly $(p<0.001)$ up regulated $(2.23 \pm 0.011$ $\mathrm{pg} / \mathrm{mL}$ ) in the serum of CFA treated animals. Administration of diclofenac, ASA, curcumin and ASA+Cur for 28 days seems to significantly lower the serum level of IL-6 (Table 3).

\section{Gastroprotective effect}

The effect ASA+Cur was evaluated using ASA induced gastric ulcer model validated by us. The result revealed that oral administration of $100 \mathrm{mg} / \mathrm{kg}$ ASA for 28

\begin{tabular}{|c|c|c|c|}
\hline $\begin{array}{l}\text { SL. } \\
\text { No }\end{array}$ & Group & $\begin{array}{c}\text { Urea } \\
(\mathrm{mg} / \mathrm{dL})\end{array}$ & $\begin{array}{l}\text { Creatinine } \\
\text { (mg/dL) }\end{array}$ \\
\hline 1 & Control & $22.6 \pm 0.004$ & $1.37 \pm 0.005$ \\
\hline 2 & CFA (0.1mL) & $30.54 \pm 0.002$ & $2.36 \pm 0.004$ \\
\hline 3 & Diclofenac $(10 \mathrm{mg} / \mathrm{kg})$ & $30.25 \pm 0.111$ & $2.30 \pm 0.003$ \\
\hline 4 & ASA (100mg/kg) & $30.26 \pm 0.12$ & $2.32 \pm 0.01$ \\
\hline 5 & Curcumin $(200 \mathrm{mg} / \mathrm{kg})$ & $27.97 \pm 0.001^{a}$ & $1.98 \pm 0.004^{a}$ \\
\hline 6 & $\begin{array}{c}\text { ASA+Cur (100 mg/ } \\
\mathrm{kg}+200 \mathrm{mg} / \mathrm{kg})\end{array}$ & $27.22 \pm 0.002^{a}$ & $1.89 \pm 0.001^{\mathrm{a}}$ \\
\hline
\end{tabular}

$a=$ Significant difference $(p<0.001)$ with respect to CFA treated group

\section{Table 3: Effect on the production of inflammatory} cytokines in the serum of arthritic rats.

\begin{tabular}{|c|c|c|c|c|}
\hline $\begin{array}{c}\text { SL. } \\
\text { No }\end{array}$ & Group & $\begin{array}{c}\text { TNF- } \alpha \\
(\mathbf{p g} / \mathrm{mL})\end{array}$ & $\begin{array}{c}\text { IL-1 } \beta \\
(\mathbf{p g} / \mathrm{mL})\end{array}$ & $\begin{array}{c}\text { IL-6 } \\
(\mathbf{p g} / \mathrm{ml})\end{array}$ \\
\hline 1 & Control & $0.91 \pm 0.014$ & $1.08 \pm 0.014$ & $0.89 \pm 0.011$ \\
\hline 2 & CFA $(0.1 \mathrm{~mL})$ & $1.66 \pm 0.015$ & $4.16 \pm 0.011$ & $2.23 \pm 0.011$ \\
\hline 3 & $\begin{array}{c}\text { Diclofenac } \\
(10 \mathrm{mg} / \mathrm{kg})\end{array}$ & $1.32 \pm 0.014^{\mathrm{a}}$ & $1.88 \pm 0.014^{\mathrm{a}}$ & $1.54 \pm 0.018^{\mathrm{a}}$ \\
\hline 4 & $\mathrm{ASA}(100 \mathrm{mg} / \mathrm{kg})$ & $1.51 \pm 0.012^{\mathrm{a}}$ & $3.62 \pm 0.017^{\mathrm{a}}$ & $1.81 \pm 0.012^{\mathrm{a}}$ \\
\hline 5 & $\begin{array}{c}\text { Curcumin } \\
(200 \mathrm{mg} / \mathrm{kg})\end{array}$ & $1.57 \pm 0.006^{\mathrm{a}}$ & $3.73 \pm 0.017^{\mathrm{a}}$ & $1.88 \pm 0.014^{\mathrm{a}}$ \\
\hline 6 & $\begin{array}{c}\mathrm{ASA}+\mathrm{Cur}(100 \\
\mathrm{mg} / \mathrm{kg}+200 \mathrm{mg} / \mathrm{kg})\end{array}$ & $1.45 \pm 0.005^{\mathrm{a}}$ & $3.31 \pm 0.015^{\mathrm{a}}$ & $1.7 \pm 0.017^{\mathrm{a}}$ \\
\hline
\end{tabular}

$\mathrm{a}=$ Significant difference $(p<0.001)$ with respect to CFA treated group

\section{Table 4: Assessment of gastroprotective activity in} rats.

\begin{tabular}{|c|c|c|c|}
\hline $\begin{array}{c}\text { SL. } \\
\text { No }\end{array}$ & Groups & $\begin{array}{c}\text { Ulcerative } \\
\text { Index (UI) }\end{array}$ & $\begin{array}{c}\text { Protective } \\
\text { Index (PI) (\%) }\end{array}$ \\
\hline 1 & Control & ------ & ----- \\
\hline 2 & ASA $(100 \mathrm{mg} / \mathrm{kg})$ & $4.07 \pm 0.033$ & ----- \\
\hline 3 & Ranitidine $(25 \mathrm{mg} / \mathrm{kg})$ & $0.76 \pm 0.033^{\text {a }}$ & 81.32 \\
\hline 4 & Curcumin $(200 \mathrm{mg} / \mathrm{kg})$ & $2.41 \pm 0.006^{\text {a }}$ & 40.78 \\
\hline
\end{tabular}

$\mathrm{a}=$ Significant difference $(p<0.001)$ with respect to ASA treated group

continual days produced ulceration in the stomach of control rats (Figure 5B and D). The UI was calculated based on ulcer score (Table 4). While ranitidine $(25 \mathrm{mg} / \mathrm{kg}$ ) treatment for 28 continual days provided $81.32 \%$ protection against ulceration, curcumin exhibited $40.78 \%$ gastro protection. Morphological and histological examination of stomach of control group showed no injury (Figure 5A and E). Further, ASA treated group showed severe disruption to the surface epithelium of mucosa and deep erosion leading to ulceration (Figure 5B). Its histology also showed leucocyte infiltration (Figure 5F). The gastric mucosal protection was evi- 


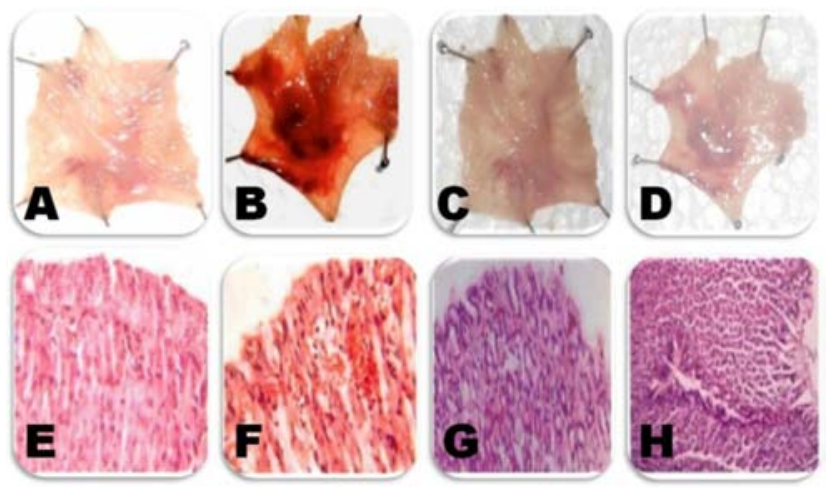

Figure 5: Representative photomicrographs of morphology and histopathology of rat stomach in ASA induced gastric ulceration model. (A and E) Control rats, (B and F) ASA $(100 \mathrm{mg} / \mathrm{kg}$ ) treated rats (C and G) Ranitidine $(25 \mathrm{mg} / \mathrm{kg})$ treated rats $(\mathrm{D}$ and $\mathrm{H})$ Curcumin $(200 \mathrm{mg} / \mathrm{kg})$ treated rats $(n=6)$.

dent in groups treated with ranitidine (Figure 5C and G). Animals treated with curcumin showed few swelling marks (Figure 5D). Although haemorrhage was not clearly evident, the histology showed congestion with superficial erosion (Figure $5 \mathrm{H}$ ).

\section{DISCUSSION}

Androgen deprivation, a treatment approach for androgen dependent prostate cancer predisposes the patients to arthritis. ${ }^{13}$ Use of non-steroidal anti-inflammatory drugs (NSAIDs) in long-term complicates the conditions owing to their adverse effects on stomach, liver and kidney. Further, in late stages when the prostate cancer becomes ADT-independent, the existing therapies are not able to manage the conditions effectively. ${ }^{12}$ ASA with potential against cancer and arthritis can be repurposed as a suitable agent, provided issues regarding its efficacy and toxicity are adequately addressed. Curcumin with strong antioxidant potential, protective ability and capacity to inhibit cancer growth can be optimised as a complementary therapy to improve efficacy and reduce toxicity against these conditions.

ASA and curcumin alone showed relatively low capability to reduce viability of prostate cancer cells (Figure 1 and S1). While ASA reduced viability of DU-145 cells by $40 \%$, the cells of LNCaP were reduced by $30 \%$ (Figure $1 \mathrm{~A}$ and $\mathrm{B}$ ). These findings are in agreement with previous reports where ASA was shown to inhibit both cells by $10-40 \% .{ }^{14-16}$ Although, curcumin at higher concentration $(50 \mu \mathrm{M})$ has earlier been shown to reduce viability of these cells by $40-50 \%$, at the tested concentration $(25 \mu \mathrm{M})$, it failed to significantly inhibit the viability $(<10 \%)$ of these prostate cancer cells (Figure 1A and B). ${ }^{35,36}$ Interestingly, when co-administered with ASA, the anticancer effects were found to better as evident from the $>60 \%$ decrease in cancer cell viability (Figure 1A and B). This is also supported by the cell shrinkage and alteration of shape which is typical features of cells going through apoptosis (Figure 1C) and inhibition of colony formation (Figure 1D). These effects were found to be better than that of the standard anticancer drug (Cisplatin) used in the study (Figure 1). The powerful anti-proliferative effect of ASA+Cur on both androgen dependent and androgen independent prostate cancer cells can be considered beneficial in the treatment of prostate cancer. This is in agreement with earlier studies where curcumin has been shown to potentiate 5-fluorouracil and doxorubicin against gastric and hepatic cancer respectively in-vitro. ${ }^{37,38}$ However, further validation in preclinical model and elucidation of the mode of this positive interaction need to be studied to establish these applications.

Arthritis induced by CFA is a chronic model in which the pathological and clinical changes resemble to human RA. ${ }^{26}$ While there are many indicators of RA, the overall effect can be quantitatively expressed as AI based on the chronic swelling induced by CFA. ${ }^{27}$ Chronic inflammation in the synovial membrane is the pathological basis of RA. ${ }^{39}$ The relative bone destruction and reduction of joint space can also be used to suggest the progress of RA. ${ }^{40}$ Based on these observations, the present study illustrates CFA induced arthritis in animals. The chronic arthritic effects are suggested by very little reduction in AI of animals treated only with CFA (Figure 2). Animals subjected to treatment with ASA, curcumin and ASA+Cur showed significantly low AI (Figure 2). Higher reduction in AI and inhibition of paw thickness by ASA+cur suggests the potentiating effects of curcumin (Figure 2 and S2). These observations are well supported by both histological and radiographic data. Prominent abnormal observations in the joints of CFA treated animals (Figure 3D) in comparison to the normal animals (Figure 3A) are supportive of this. While both ASA and curcumin reduced synovial hyperplasia, they failed (Figure 3J and $\mathrm{M}$ ) to achieve effective protection against arthritis in comparison to the diclofenac. However, when animals were treated with ASA+Cur, the overall protection against arthritis was found to be effective (Figure 3P) as comparable to that of the diclofenac (Figure 3G). In support of the above findings radiological examinations revealed soft tissue swelling and bony destruction in arthritic rats (Figure 3E and F). While administration of diclofenac minimised the bone destruction and swelling of the joint (Figure 3H and I), treatment with ASA (Figure $3 \mathrm{~K}$ and L) and 
curcumin (Figure $3 \mathrm{~N}$ and $\mathrm{O}$ ) could not effectively manage these conditions. The effects of ASA+Cur was similar to those observed with standard group, as evident from reduced soft tissue swelling, bone destruction as well as joint space narrowing (Figure 3Q and R).

Elevated level of ESR is a sign of inflammation in the body related to higher concentration of plasma proteins, especially globulins ( $\alpha$ and $\beta$ globulins). ${ }^{41,42}$ Furthermore, higher expression of RF is a strong indicator of RA. ${ }^{43,44}$ Accordingly, rats treated only with CFA showed highest level of ESR and RF. As expected these parameters were found to be minimum in animals treated with diclofenac. Although curcumin and ASA significantly $(p<0.001)$ lowered ESR and RF in animals, the effects were more pronounced in animals treated with ASA+Cur (Table 1). Enhanced ESR and RF level are usually associated with higher level of cytokines including TNF- $\alpha$, IL- $1 \beta$ and IL- 6 . Higher levels of these factors facilitate auto-immune conditions leading to destruction of cartilage and bone. ${ }^{45-47}$ Accordingly the levels of these factors (Table 3) are in agreement with the higher level of ESR and RF observed in arthritis induced rats. Further, decrease in the level of ESR and $\mathrm{RF}$ also correlates well with the decrease in these cytokines in animals treated with diclofenac. The relatively higher reduction of these factors in animals receiving ASA+Cur also supports our earlier findings where the efficacy was higher compared to either curcumin or ASA. Earlier curcumin has been shown to significantly improve anti-arthritic effects of methotrexate. ${ }^{48}$ Thus these findings suggest complementary benefits of curcumin against arthritis.

While RA is a prominent risk factor for kidney dysfunction, use of NSAIDs to manage RA often pre-dispose to this. ${ }^{49}$ Accordingly, the suitability of medicinal agents can also be justified by estimating their capacity to protect the kidney function. Urea and creatinine are routinely excreted by kidney. Thus the functional ability of kidney is adjudged by the level of these waste products in serum. The higher level of the urea and creatinine in serum of CFA treated rats corroborates the nephrotoxicity effects either directly by CFA or by other induced inflammatory parameters. The failure of diclofenac and ASA to prevent these conditions can be justified by the fact that majority of NSAIDs are themselves known to be nephrotoxic on chronic use. ${ }^{50}$ However, serum urea and creatinine level was significantly $(p<0.001)$ lowered by curcumin following administration for 28 days. Interestingly, it was also able to lower the kidney dysfunction when co-used with ASA (ASA+Cur) during these periods (Table 2 and Figure 4).
Gastrotoxicity delimits the application of ASA. Curcumin showed the ability to reduce ASA-induced damage to mucosa (Figure 4D and $\mathrm{H}$ ). Although the effects were relatively less compared to ranitidine (Table 4), it suggest about the benefits of its complementary use with ASA. The positive interaction potential of curcumin against prostate cancer, arthritis and ability to prevent nephrotoxicity as well as gastrotoxicity suggest its suitability for complementary use along with ASA against prostate cancer. However, further in-vivo validation against prostate cancer is required to justify their application.

\section{CONCLUSION}

From the above studies, it can be concluded that optimisation of existing drugs and repositioning them against new indications is an interesting approach to address therapeutic challenges. The multifunctional curcumin is ideal option to enhance the scope of application of ASA. The inherent anticancer effect of ASA was found to be enhanced by co-used with curcumin against prostate cancer cell lines. Positive interaction was also observed against CFA induced arthritis. Further, curcumin protected against kidney dysfunction associated with arthritis and use of NSAIDs. Besides, the moderate gastro-protection observed with curcumin demonstrates its ability to lower the gastric damage caused by ASA. These findings might encourage repositioning of ASA against prostate cancer by using curcumin as a complementary therapy. Further studies in higher animals and different strengths may be necessary to optimise the combination and maximise the therapeutic benefits which in turn pave the way for the product development and commercialisation there by provide benefit to the society.

\section{ACKNOWLEDGEMENT}

The authors are grateful to School of Pharmaceutical Sciences, Siksha 'O' Anusandhan (Deemed to be University), Bhubaneswar, India for providing financial assistance in the form of fellowship to make this work successful.

\section{CONFLICT OF INTEREST}

The authors declare no conflict of interest.

\section{ABBREVIATIONS}

p.o: Per os; ASA: Acetylsalicylic acid; COX: Cyclooxygenase; NF- $\boldsymbol{~} \mathbf{B}$ : Nuclear factor kappa-light- 
chain-enhancer of activated B cells; ADT: Androgen deprivation therapy; ASA+Cur: Curcumin on coadministration with ASA; ATCC: American Type Culture Collection; DMEM: Dulbecco's Modified Eagle Media; CPCSEA: Committee for the Purpose of Control And Supervision of Experiments on Animals; IAEC: Institutional Animal Ethics Committee; MTT:(3-(4, 5-dimethylthiazol-2-yl)-2, 5-diphenyltetrazolium bromide; DMSO: Dimethyl sulfoxide; CV: Cell viability; PBS: Phosphate-buffered saline; SF: Surviving fraction; CFA: complete Freund's adjuvant; CMC: Carboxy methyl cellulose; AI: Arthritis index; $\mathbf{H}$ and E: Hematoxylin-eosin; ESR: Erythrocyte sedimentation rate; RF: Rheumatoid factor; RA: Rheumatoid arthritis; TMB: Tetramethylbenzidine; TNF- $\alpha$ : Tumor necrotic factor $\alpha$; IL-1 $\beta$ : Interleukin 1 $\beta$; IL-6: Interleukin 6; UI: Ulcer index; PI: Protective index; NSAIDs: Non-steroidal anti-inflammatory drugs.

\section{REFERENCES}

1. Talevi A. Drug repositioning: Current approaches and their implications in the precision medicine era. Expert Rev Precis Med Drug Dev. 2018;3(1):49-61.

2. Yoo JH, Yim SV, Lee BC. Study of Pharmacodynamic and Pharmacokinetic Interaction of Bojungikki-Tang with Aspirin in Healthy Subjects and Ischemic Stroke Patients. Evid-Based Complement Alternat Med. 2018;1-7. (Article 9727240).

3. Din FV, Theodoratou E, Farrington SM, Tenesa A, Barnetson RA, Cetnarskyj R, et al. Effect of aspirin and NSAIDs on risk and survival from colorectal cancer. Gut. 2010;59(12):1670-9.

4. Pathi S, Jutooru I, Chadalapaka G, Nair V, Lee SO, Safe S. Aspirin inhibits colon cancer cell and tumor growth and down regulates specificity protein (Sp) transcription factors. Plos One. 2012;7(10):1-14.

5. Hossain MA, Kim DH, Jang JY, Kang YJ, Yoon JH, Moon JO, et al. Aspirin induces apoptosis in vitro and inhibits tumor growth of human hepatocellular carcinoma cells in a nude mouse xenograft model. Int $\mathrm{J}$ Oncol. 2012;40(4):1298-304.

6. Din FV, Dunlop MG, Stark LA. Evidence for colorectal cancer cell specificity of aspirin effects on NFKB signalling and apoptosis. $\mathrm{Br} \mathrm{J}$ Cancer. 2004;91(2):381-8.

7. McCarty MF, Block KI. Pre-administration of high-dose salicylates, suppressors of NF-KB activation may increase the chemosensitivity of many cancers: An example of proapoptotic signal modulation therapy. Integr Cancer Ther. 2006;5(3):252-68.

8. Whitehouse MW, Rainsford KD. Prevention of the gastrotoxicity of aspirin and related drugs in rats by lithium salts and sodium thiocyanate. Toxicol Appl Pharmacol. 1983;68(2):323-7.

9. Asif S, Mudassir S, Toor RS. Histological Effects of Nigella Sativa on Aspirin-Induced Nephrotoxicity in Albino Rats. J Coll Physicians Surg Pak. 2018;28(10):735-8.

10. Aprioku JS, Uche FI. Renal effects of non-steroidal anti-inflammatory drugs in albino rats. Br J Pharmacol. 2013;3(3):314-25.

11. Jain S, Saxena S, Kumar A. Epidemiology of prostate cancer in India. Meta Gene. 2014;2:596-605.

12. Saraon P, Drabovich AP, Jarvi KA, Diamandis EP. Mechanisms of androgenindependent prostate cancer. Ejifcc. 2014;25(1):42-54.

13. Yang DD, Krasnova A, Nead KT, Choueiri TK, Hu JC, Hoffman KE, et al. Androgen deprivation therapy and risk of rheumatoid arthritis in patients with localized prostate cancer. Ann Oncol. 2017;29(2):386-91.
14. He Y, Huang H, Farischon C, Li D, Du Z, Zhang K, et al. Combined effects of atorvastatin and aspirin on growth and apoptosis in human prostate cancer cells. Oncol Rep. 2017;37(2):953-60.

15. Rotem R, Tzivony Y, Flescher E. Contrasting effects of aspirin on prostate cancer cells: Suppression of proliferation and induction of drug resistance. Prostate. 2000;42(3):172-80.

16. Shi C, Zhang N, Feng Y, Cao J, Chen X, Liu B. Aspirin inhibits IKK- $\beta$-mediated prostate cancer cell invasion by targeting matrix metalloproteinase- 9 and urokinase-type plasminogen activator. Cell Physiol Biochem. 2017;41(4):1313-24.

17. Morris T, Stables M, Hobbs A, DeSouza P, Colville-Nash P, Warner T, et al. Effects of low-dose aspirin on acute inflammatory responses in humans. J Immunol. 2009;183(3):2089-96.

18. Davis JD, Struth AG, Turner RA, Pisko EJ, Ruchte IR. Pirprofen and aspirin in the treatment of rheumatoid arthritis. Clin Pharmacol Ther. 1979;25(5 part 1):618-23.

19. Killian $\mathrm{PH}$, Kronski E, Michalik KM, Barbieri O, Astigiano S, Sommerhoff CP, et al. Curcumin inhibits prostate cancer metastasis in-vivo by targeting the inflammatory cytokines CXCL1 and-2. Carcinogenesis. 2012;33(12):2507-19.

20. Daily JW, Yang M, Park S. Efficacy of turmeric extracts and Curcumin for alleviating the symptoms of joint arthritis: A systematic review and metaanalysis of randomized clinical trials. J Med Food. 2016;19(8):717-29.

21. Morsy MA, El-Moselhy MA. Mechanisms of the protective effects of curcumin against indomethacin-induced gastric ulcer in rats. Pharmacol. 2013; 91(5-6):267-74.

22. Mohapatra TK, Nayak RR, Subudhi BB. Exploration of anti-inflammatory and hepatoprotective effect of curcumin on co-administration with acetylsalicylic acid. J Pharm Pharmacogn Res. 2019;7(5):310-22.

23. Omar HA, Arafa ES, Maghrabi IA, Weng JR. Sensitization of Hepatocellular Carcinoma Cells to A po2 L/TRAIL by a Novel Akt/NF-k B Signalling Inhibitor. Basic Clin Pharmacol. 2014;114(6):464-71.

24. Wang C, Zhou X, Xu H, Shi X, Zhao J, Yang M, et al. Niclosamide Inhibits Cell Growth and Enhances Drug Sensitivity of Hepatocellular Carcinoma Cells via STAT3 Signaling Pathway. J Cancer. 2018;9(22):4150-5.

25. Newbould BB. Chemotherapy of arthritis induced in rats by injection of Mycobacterial adjuvant. Br J Pharmacol Chemother. 1963;21(1):127-36.

26. Ekambaram S, Perumal SS, Subramanian V. Evaluation of antiarthritic activity of Strychnos potatorum Linn seeds in Freund's adjuvant induced arthritic rat model. BMC Complement Altern Med. 2010;10(1):56-63.

27. Coelho MG, Reis PA, Gava VB, Marques PR, Gayer CR, Laranja $\mathrm{GA}$, et al. Anti-arthritic effect and subacute toxicological evaluation of Baccharisgenistelloides aqueous extract. Toxicol Lett. 2004;154(1-2):69-80.

28. Liu JY, Hou YL, Cao R, Hong X, Qiu HX, Cheng GH, et al. Protodioscin ameliorates oxidative stress, inflammation and histology outcome in Complete Freund's adjuvant induced arthritis rats. Apoptosis. 2017;22(11):1454-60.

29. Anderson GD, Hauser SD, McGarity KL, Bremer ME, Isakson PC, Gregory SA. Selective inhibition of cyclooxygenase (COX)-2 reverses inflammation and expression of COX-2 and interleukin 6 in rat adjuvant arthritis. J Clin Invest. 1996;97(11):2672-9.

30. Mehta A, Sethiya NK, Mehta C, Shah GB. Anti-arthritis activity of roots of Hemidesmus indicus R. Br. (Anantmul) in rats. Asian Pac J Trop Med. 2012;5(2):130-5.

31. Bourque JG, Smart M, Wobese G. Monensis toxicity in lambs. Can Vet J. 1986;27(10):397-9.

32. Sharma S, Sahu D, Das HR, Sharma D. Amelioration of collagen-induced arthritis by Salix nigra bark extract via suppression of pro-inflammatory cytokines and oxidative stress. Food Chem Toxicol. 2011;49(12):3395-406.

33. Onasanwo SA, Singh N, Olaleye SB, Palit G. Anti-ulcerogenic and proton pump $(\mathrm{H}+, \mathrm{K}+$ ATPase) inhibitory activity of Kolaviron from Garcinia kola Heckel in rodents. Indian J Exp Biol. 2011;49(6):461-8.

34. Mohapatra TK, Sarkar P, Dash RN, Moharana AK, Subudhi BB. Evaluation of complementary effects of turmeric, ginger and cinnamon with aspirin. Indian Drugs. 2018;55(7):28-34.

35. Yang J, Wang C, Zhang Z, Chen X, Jia Y, Wang B, et al. Curcumin inhibits the survival and metastasis of prostate cancer cells via the Notch-1 signaling pathway. Apmis. 2017;125(2):134-40. 
36. $\mathrm{Hu} \mathrm{HJ}$, Lin $\mathrm{XL}$, Liu $\mathrm{MH}$, Fan $\mathrm{XJ}$, Zou WW. Curcumin mediates reversion of HGF induced epithelial-mesenchymal transition via inhibition of c-Met expression in DU145 cells. Oncology Letters. 2016;11(2):1499-505.

37. Yang $\mathrm{H}$, Huang $\mathrm{S}$, Wei $\mathrm{Y}$, Cao $\mathrm{S}, \mathrm{Pi} \mathrm{C}$, Feng $\mathrm{T}$, et al. Curcumin Enhances the Anticancer Effect Of 5 -fluorouracil against Gastric Cancer through Down-Regulation of COX-2 and NF-kB Signaling Pathways. J Cancer. 2017;8(18):3697-706.

38. Notarbartolo M, Poma P, Perri D, Dusonchet L, Cervello M, D'Alessandro N. Antitumor effects of curcumin, alone or in combination with cisplatin or doxorubicin, on human hepatic cancer cells. Analysis of their possible relationship to changes in NF-kB activation levels and in IAP gene expression. Cancer Lett. 2005;224(1):53-65.

39. Islander $\mathrm{U}$, Jochems $\mathrm{C}$, Lagerquist MK, Forsblad-d'Elia $\mathrm{H}$, Carlsten $\mathrm{H}$. Estrogens in rheumatoid arthritis: The immune system and bone. Mol Cell Endocrinol. 2011;335(1):14-29.

40. Hu F, Hepburn HR, Li Y, Chen M, Radloff SE, Daya S. Effects of ethanol and water extracts of propolis (bee glue) on acute inflammatory animal models. J Ethnopharmacol. 2005;100(3):276-83.

41. Koes BW, Bouter LM. On the accuracy of history, physical examination and erythrocyte sedimentation rate in diagnosing low back pain in general practice:A criteria-based review of the literature. Spine. 1995;3(1):318-27.

42. Nielen MM, Schaardenburg VD, Reesink HW, Twisk JW, DeStadt RJV, DerHorst-Bruinsma IE, et al. Simultaneous development of acute phase response and auto antibodies in preclinical rheumatoid arthritis. Ann Rheum Dis. 2006;65(4):535-7.
43. Yildirim K, Karatay S, Melikoglu MA, Gureser G, Ugur M, Senel K. Associations between acute phase reactant levels and disease activity score (DAS28) in patients with rheumatoid arthritis. Ann Clin Lab. 2004;34(4):423-6.

44. Rossi D, Modena V, Sciascia S, Roccatello D. Rheumatoid arthritis: biological therapy other than anti-TNF. Int Immunopharmacol. 2015;27(2):185-8.

45. Brown KD, Claudio E, Siebenlist $U$. The roles of the classical and alternative nuclear factor-kappa B pathways: Potential implications for autoimmunity and rheumatoid arthritis. Arthritis Res Ther. 2008;10(4):212-8.

46. Talstad I, Haugen HF. The relationship between the erythrocyte sedimentation rate (ESR) and plasma proteins in clinical materials and models. Scand J Clin Lab Invest. 1979;39(6):519-24.

47. Hickson LJ, Crowson CS, Gabriel SE, McCarthy JT, Matteson EL. Development of reduced kidney function in rheumatoid arthritis. Am J Kidney Dis. 2014;63(2):206-13.

48. Banji D, Pinnapureddy J, Banji OJ, Kumar AR, Reddy KN. Evaluation of the concomitant use of methotrexate and curcumin on Freund's complete adjuvant-induced arthritis and hematological indices in rats. Indian J Pharmacol. 2011;43(5):546-50.

49. Aycan IO, Elpek O, Akkaya B, Kirac E, Tuzcu H, Kaya S, et al. Diclofenac induced gastrointestinal and renal toxicity is alleviated by thymoquinone treatment. Food Chem Toxicol. 2018;118:795-804

50. Calder IC, Funder CC, Green CR, Ham KN, Tange JD. Comparative nephrotoxicity of aspirin and phenacetin derivatives. $\mathrm{Br}$ Med $\mathrm{J}$. 1971;4(5786):s518-s21.

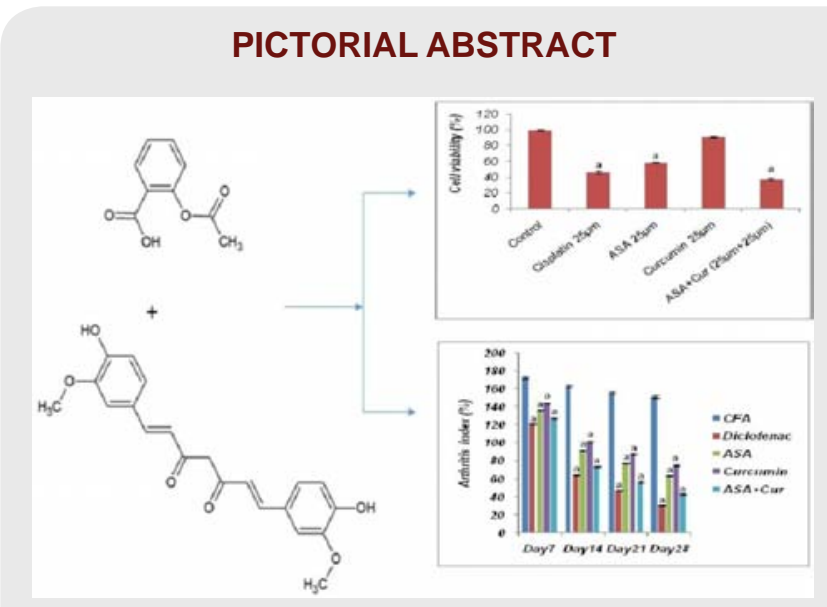

\section{SUMMARY}

The present study emphasizes co-administration of curcumin with ASA enhance the efficacy of ASA against both androgen dependent and nondependent prostate cancer and associated arthritis. Though arthritis is not curable, the co-used not only reduce arthritis related severe complications and discomfort but also proved to produce moderate gastro-protection which is a serious challenge of ASA administration at anticancer dose. Further co-administration also reduced TNF- $\alpha$, IL- $1 \beta$ and IL- 6 at the molecular level quantitatively proved its anti-inflammatory action thus decreasing the risk of nephrotoxicity.

\section{About Authors}

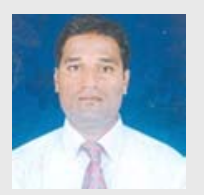

Dr. Bharat Bhusan Subudhi: Working as a Professor at School of Pharmaceutical Sciences, Siksha O Anusandhan Deemed to be University, Bhubaneswar, Odisha. He has completed his postgraduation in Pharmaceutical chemistry from Utkal University, Bhubaneswar, Odisha and Ph.D. in Pharmaceutical Sciences from Utkal University in 2008. He has more than 15 years of research experience in the field of drug development and analysis. He has published more than 60 research papers and filed 3 patents. He has handled various research projects related to pharmacodynamic optimization of leads for new drug development. Optimization of pharmacokinetic for drug repositioning is also one of his research area. 
Mr. Tapas Kumar Mohapatra: He did B. Pharm from BPUT, Rourkela, Odisha in 2006 and M.Pharm in Pharmacology from BPUT, Rourkela, in 2008. He has nine years of teaching experience. Presently he is pursuing his Ph.D (Research Scholar), in School of Pharmaceutical Sciences, under SOA deemed to be University, Bhubaneswar, Odisha.

Mr. Debasish Mohapatra: He did M. Phil from PG Department of Zoology, Utkal University, Bhubaneswar, Odisha. Presently he is pursuing his Ph.D in the Institute of Life Sciences, Bhubaneswar, Odisha in the area of cancer biology.

Cite this article: Mohapatra TK, Mohapatra D, Subudhi BB. Complimentary Effects of Curcumin for Enhancing Efficacy of Acetylsalicylic Acid against Prostate Cancer. Indian J of Pharmaceutical Education and Research. 2019;53(4s):s666-s677. 